\title{
Primary Care, Economic Barriers to Health Care, and Use of Colorectal Cancer Screening Tests Among Medicare Enrollees Over Time
}

\author{
Cbyke A. Doubeni, MD, MPH',2 \\ Adeyinka O. Laiyemo, $M D, M P H^{3}$ \\ Angela C. Young, BS ${ }^{1}$ \\ Carrie N. Klabunde, $P b D^{4}$ \\ George Reed, PbD \\ Terry S. Field, DSc ${ }^{2}$ \\ Robert H. Fletcher, MD, MSc ${ }^{6}$ \\ 'Department of Family Medicine and Com- \\ munity Health, University of Massachusetts \\ Medical School, Worcester, Massachusetts \\ ${ }^{2}$ Meyers Primary Care Institute, University \\ of Massachusetts Medical School, Fallon \\ Clinic, Fallon Community Health Plan, \\ Worcester, Massachusetts \\ ${ }^{3}$ Cancer Prevention Fellowship Program, \\ Division of Cancer Prevention, National \\ Cancer Institute, Bethesda, Maryland \\ ${ }^{4}$ Division of Cancer Control and Popula- \\ tion Sciences, National Cancer Institute, \\ Bethesda, Maryland \\ ${ }^{5}$ Division of Preventive and Behavioral \\ Medicine, Department of Medicine, Uni- \\ versity of Massachusetts Medical School, \\ Worcester, Massachusetts \\ ${ }^{6}$ Department of Population Medicine, \\ Harvard Medical School, Boston, \\ Massachusetts
}

Conflicts of interest: The authors bave no relevant financial interests or conflict of interests.

\section{CORRESPONDING AUTHOR}

Chyke A. Doubeni, MD, MPH

Department of Family Medicine and Community Health

University of Massachusetts Medical School 55 Lake Ave N

Worcester, MA 01655

Chyke.Doubeni@umassmed.edu

\begin{abstract}
PURPOSE Colorectal cancer (CRC) screening remains underutilized. The objective of this study was to examine the impact of primary care and economic barriers to health care on CRC testing relative to the 2001 Medicare expansion of screening coverage.
\end{abstract}

METHODS Medicare Current Beneficiary Survey data were use to study community-dwelling enrollees aged 65 to 80 years, free of renal disease and CRC, and who participated in the survey in $2000(n=8,330), 2003(n=7,889)$, or 2005 $(n=7,614)$. Three outcomes were examined: colonoscopy/sigmoidoscopy within 5 years (recent endoscopy), endoscopy more than 5 years previously, and fecal occult blood test (FOBT) within 2 years.

RESULTS Endoscopy use increased and FOBT use decreased during the 6-year period, with no significant independent differences between those receiving care from primary care physicians and those receiving care from other physicians. Beneficiaries without a usual place of health care were the least likely to undergo CRC testing, and that gap widened with time: adjusted odds ratio (AOR) $=0.27$ (95\% confidence interval $[\mathrm{Cl}], 0.19-0.39)$ for FOBT, and $\mathrm{AOR}=0.35(95 \% \mathrm{Cl}, 0.27-0.46)$ for endoscopy in 2000 compared with $A O R=0.18(95 \% \mathrm{Cl}, 0.11-0.30)$ for FOBT and $A O R=0.22$ (95\% Cl, 0.17-0.30) for endoscopy in 2005. Disparities in use of recent endoscopy by type of health insurance coverage in both 2000 and 2005 were greater for enrollees with a high school education or higher than they were for less-educated enrollees. There were no statistically significant differences by delayed care due to cost after adjustment for health insurance.

CONCLUSION Despite expanding coverage for screening, complex CRC screening disparities persisted based on differences in the usual place and cost of health care, type of health insurance coverage, and level of education.

Ann Fam Med 2010;8:299-307. doi:10.1370/afm.1112.

\section{INTRODUCTION}

$\mathrm{D}$ espite the acknowledged effectiveness of colorectal cancer (CRC) screening, ${ }^{1-3}$ nearly one-half of eligible US adults have not been tested as recommended by national guidelines..$^{4.7}$ Although primary care has a well-established role in the delivery of CRC screening services, ${ }^{8-11}$ there are only limited published findings of the impact of not receiving regular health care from a primary care physician.

Lack of a regular place of health care or adequate health insurance and limited income contribute to underuse of CRC screening. ${ }^{12-15}$ The impact of these factors may be compounded by the recent increasing use of colonoscopy, the most expensive screening test ${ }_{1}^{16,17}$ as the preferred method of screening. ${ }^{4,5,7,18-20}$ These relationships are not well known, however.

Medicare enrollees are an excellent population in which to study the effect of health care access and utilization patterns on use of CRC screen- 
ing. Medicare enrollees are a heterogeneously insured population. Some enrollees are eligible for Medicaid, but most supplement their benefits with additional private insurance. ${ }^{21}$ In 2001, Medicare changed its policy on CRC screening to include reimbursement for screening colonoscopy for those at average risk as defined by national guidelines. An important question is whether this expansion of benefits reduced disparities associated with the type of health insurance coverage, income, or usual place of health care?

In this report, we examine the impact of not receiving regular care from primary care physicians and economic barriers to health care on CRC testing in the period before and after Medicare's policy change.

\section{METHODS}

Medicare Current Beneficiary Survey (MCBS) Access to Care data were used for this report. MCBS is an ongoing annual survey of nationally representative samples of beneficiaries. ${ }^{22}$ The methods for data collection for the MCBS have been described in detail previously. ${ }^{22,23}$ We restricted this report to noninstitutionalized beneficiaries aged 65 to 80 years who did not have end-stage renal disease or CRC and were interviewed during 2000, 2003, and 2005. Our upper age cutoff is consistent with current national guidelines $^{24}$ and prevailing quality indicator measures for CRC screening during the period under study. ${ }^{25}$

\section{Data Elements}

The MCBS collects data on beneficiaries' place of residence, demographic and socioeconomic characteristics, height and weight, self-rated general health, and personal history of cancer other than skin cancer. We categorized race-ethnicity as non-Hispanic whites, nonHispanic blacks, Hispanics vs others; marital status as married, widowed, divorced/separated vs never married; the primary interview language as English vs other languages; and educational achievement as less than high school graduate vs high school graduate and higher. Data were collected on the annual household income of study participants, which we categorized as less than $\$ 25,000$ vs higher.

We categorized type of health insurance coverage into 3 mutually exclusive groups: Medicare Part B only (Medicare-only), Medicare plus Medicaid (MedicareMedicaid), and supplemental insurance (comprised of Medicare health maintenance organization, and employer-sponsored or self-purchased insurance). We categorized the setting in which enrollees received their usual care by their response to specialty of the "particular doctor [an enrollee] usually sees..." at the "place [he/she] usually goes to when...sick or for advice about...health" as primary care physician (internists, family physicians, or general practitioners), nonprimary care physician, and no usual source of care. We derived a variable on delayed medical care because of cost based on endorsement of any of the questions that asked whether a beneficiary delayed care in the previous year, did not have a usual place of care, did not see a doctor for a medical problem, or did not fill a prescription because of cost. ${ }^{23,26}$

\section{Measures of CRC Testing}

MCBS respondents were asked whether they had ever had a screening sigmoidoscopy or colonoscopy or home fecal occult blood test (FOBT) and the time of the most recent test (recorded as less than 1 year, 1 to 2 years, 2 to 3 years, 3 to 5 years, or 5 or more years ago). ${ }^{23,26}$ The MCBS did not distinguish between sigmoidoscopy and colonoscopy, and there were no questions on barium enema or computed tomographic colonography. We therefore categorized the patterns of testing into 3 mutually exclusive groups based on prevailing guidelines ${ }^{27}$ defined hierarchically as endoscopy within 5 years with or without FOBT testing (recent endoscopy), FOBT within 2 years, and endoscopy more than 5 years previously. The 2 -year cutoff for FOBT testing accommodates slight deviations from the recommended yearly schedule for the test. ${ }^{23}$

\section{Data Analyses}

Single and multiple predictor logistic regression models were used to examine trends in patterns of screening and the relationship with lack of supplemental insurance, self-reported economic barriers, and the usual setting of medical care. Trends in use of FOBT and endoscopy during the 6 -year period were determined using pooled data from the 3 survey years. ${ }^{28}$

We used multinomial logistic regression models to examine the relationship between selected health care access and utilization indicators and screening patterns. These analyses were stratified by study year and restricted to the 2000 and 2005 survey years to compare patterns for the most recent year with those for the period before Medicare's expansion of benefits. Candidate covariates in the multivariable models were selected from the data elements described above, as well as census region of residence using a priori and model fit considerations. ${ }^{29,30} \mathrm{We}$ assessed the significance of 2-way interactions between selected covariates using the Wald test, with the Bonferonni correction for multiple comparisons of coefficients. ${ }^{31}$ To assess whether colinearity affected our results, a base model was constructed comprised of age, sex, race-ethnicity, interview language, place of residence, and self-reported health status. To these elements were added usual place of care, insur- 
ance, education, income, and delayed care in various combinations, and we found no evidence for an impact of potential colinearity on the results. Cross-sectional survey weights were used in all analyses, and variance estimations accounted for the complex survey design.

The analyses were performed using Stata 10.0 (StataCorp LP, College Station, Texas).

\section{RESULTS}

\section{Characteristics}

Of the Medicare beneficiaries included in the analyses, 8,330 were interviewed in $2000,7,889$ in 2003, and 7,614 in 2005 (Table 1). The age, race, sex, and marital status distributions were similar across the 3 survey years. During the 6-year period, an increasing proportion of enrollees reported having at least a high school diploma or an annual income of $\$ 25,000$ or higher. Over the study period, the proportion with supplemental insurance decreased, the proportion who delayed care was unchanged, and the proportion seeing primary care physicians increased.

Those without a usual source of health care were less likely to have supplemental insurance (data not shown). Compared with those who usually received health care from primary care physicians, those receiving care from non-primary care physicians were more likely to report that they were in poor health (unadjusted odds ratio $[\mathrm{OR}]=1.42 ; 95 \%$ confidence interval [CI], 1.27-1.60), but those without a usual source of care were less likely to report poor health $(\mathrm{OR}=0.70 ; \mathrm{CI}, 0.59-0.84)$.

\section{Trends in Patterns of Screening}

During the 6-year period, there was a statistically significant increase in the use of lower gastrointestinal endoscopy and a decrease in the proportion of those who had used FOBT alone or had not undergone guidelines-concordant screening (Table 1). The majority of reported endoscopic examinations were performed within 5 years of the interview dates. About $17 \%$ of enrollees reported both recent endoscopy and FOBT during each of the 3 survey years (data not shown).
Table 1. Characteristics of the Study Population: MCBS 2000-2005

\begin{tabular}{|c|c|c|c|c|}
\hline \multirow[b]{2}{*}{ Characteristics } & \multicolumn{3}{|c|}{ Survey Year ${ }^{\mathrm{a}}$} & \multirow[b]{2}{*}{$\begin{array}{c}P \\
\text { Value }\end{array}$} \\
\hline & $\begin{array}{c}2000 \\
(n=8,330)\end{array}$ & $\begin{array}{c}2003 \\
(n=7,889)\end{array}$ & $\begin{array}{c}2005 \\
(n=7,614)\end{array}$ & \\
\hline \multicolumn{5}{|l|}{ Age groups, \% } \\
\hline $65-69$ y & 33.5 & 35.0 & 35.5 & .01 \\
\hline $70-74$ y & 36.5 & 35.1 & 34.4 & .01 \\
\hline $75-80$ y & 30.1 & 30.0 & 30.1 & $>.99$ \\
\hline \multicolumn{5}{|l|}{ Race-ethnicity, \% } \\
\hline White & 81.0 & 79.7 & 79.2 & .15 \\
\hline Blacks & 8.2 & 8.2 & 8.2 & $>.99$ \\
\hline Hispanic & 7.0 & 7.7 & 7.7 & .44 \\
\hline others & 3.8 & 4.4 & 4.9 & .02 \\
\hline Sex, women, \% & 55.8 & 54.9 & 54.8 & .17 \\
\hline \multicolumn{5}{|l|}{ Marital status, $\%$} \\
\hline Married & 61.3 & 61.7 & 62.4 & .21 \\
\hline Widowed & 25.4 & 24.9 & 23.2 & .01 \\
\hline Divorced/separated & 9.7 & 10.4 & 11.3 & .001 \\
\hline Never married & 3.6 & 3.0 & 3.1 & .10 \\
\hline \multicolumn{5}{|l|}{ Body mass index, $\mathrm{kg} / \mathrm{m}^{2}, \%$} \\
\hline$<25$ & 39.4 & 37.6 & 37.1 & .02 \\
\hline $25-30$ & 38.9 & 38.3 & 38.5 & .43 \\
\hline$>30$ & 21.7 & 24.1 & 23.5 & $<.001$ \\
\hline Language of interview, English, \% & 96.5 & 95.9 & 95.9 & .18 \\
\hline Less than high school, \% & 30.1 & 27.4 & 24.5 & $<.01$ \\
\hline $\begin{array}{l}\text { Annual household income } \\
<\$ 25,000, \%\end{array}$ & 57.7 & 52.1 & 48.9 & $<.01$ \\
\hline Residing in a metropolitan area, \% & 76.3 & 76.8 & 76.4 & .90 \\
\hline \multicolumn{5}{|l|}{ Medicare insurance type, \% } \\
\hline Medicare part B only & 9.3 & 12.4 & 12.3 & $<.01$ \\
\hline Medicare-Medicaid & 9.6 & 11.4 & 11.3 & .02 \\
\hline $\begin{array}{l}\text { Medicare with supplemental } \\
\text { insurance }\end{array}$ & 81.1 & 76.2 & 76.4 & $<.01$ \\
\hline \multicolumn{5}{|l|}{$\begin{array}{l}\text { Usual place of medical care and } \\
\text { physician, \% }\end{array}$} \\
\hline Primary care & 78.1 & 82.4 & 82.0 & $<.01$ \\
\hline Non-primary care & 14.7 & 12.0 & 12.5 & .01 \\
\hline No usual place of care & 7.1 & 5.7 & 5.5 & .001 \\
\hline Delayed medical care due to cost & 7.3 & 8.2 & 7.6 & .42 \\
\hline $\begin{array}{l}\text { History of non-skin cancer } \\
\text { except CRC }\end{array}$ & 15.1 & 15.8 & 15.8 & .22 \\
\hline General health fair-to-poor & 21.7 & 21.5 & 19.9 & .04 \\
\hline \multicolumn{5}{|l|}{ Colorectal cancer testing, $\%^{\mathrm{b}}$} \\
\hline Unscreened & 39.2 & 35.0 & 31.7 & $<.01$ \\
\hline Endoscopy $>5$ y previously & 8.0 & 8.8 & 9.0 & $<.01$ \\
\hline FOBT within 2 y & 14.9 & 11.7 & 10.4 & .04 \\
\hline Recent endoscopy & 37.8 & 44.5 & 48.9 & $<.01$ \\
\hline \multicolumn{5}{|c|}{ FOBT = home fecal occult blood test; MCBS = Medicare Current Beneficiary Survey. } \\
\hline \multicolumn{5}{|c|}{$\begin{array}{l}\text { a The weighted population estimates for those included in the analyses were for year } 2000, \mathrm{~N}=22,329,320 \text {; } \\
\text { year } 2003, \mathrm{~N}=22,601,377 \text {; year } 2005, \mathrm{~N}=22,548,092 \text {. Column percents may not sum to } 100 \% \text { because of } \\
\text { rounding error. } \\
{ }^{\mathrm{b}} \text { Colorectal cancer testing categories are mutually exclusive. }\end{array}$} \\
\hline
\end{tabular}


Figure 1. Patterns of colorectal testing by usual place of medical care among Medicare enrollees aged 65 to 80 years: MCBS $2000-2005$.

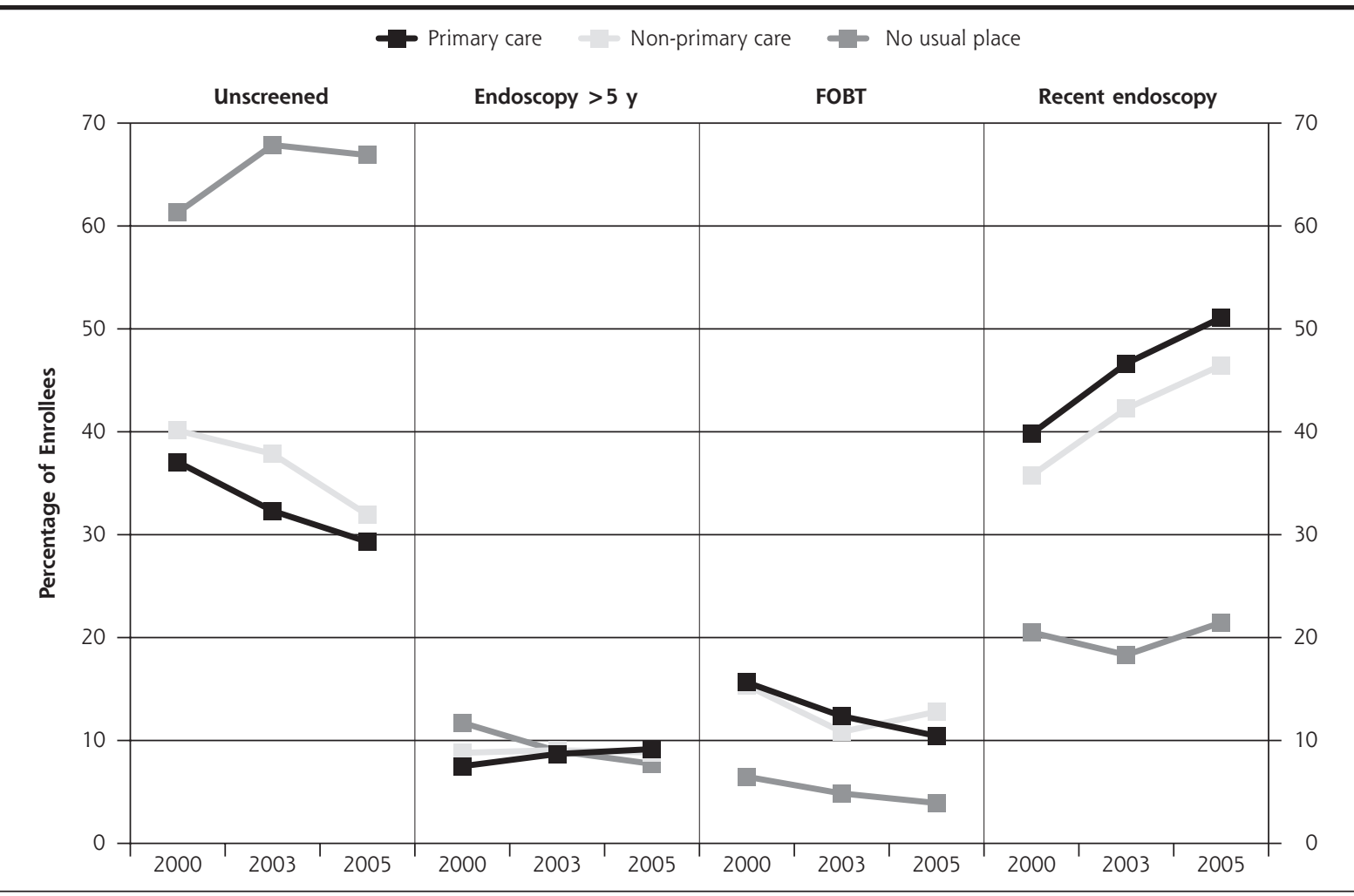

Endoscopy $=$ sigmoidoscopy or colonoscopy; FOBT = home fecal occult blood test; $\mathrm{MCBS}=$ Medicare Current Beneficiary Survey; unscreened $=$ enrollees who had never before been screened or only reported FOBT more than 2 years previously.

Note: colorectal cancer testing categories are mutually exclusive.

Figure 1 shows the trends in CRC testing by the specialty of the usual physician. Those who received regular care from primary care physicians had the highest rates of testing, and they had increasing rates of recent endoscopy and decreasing rates of FOBT use over time. Among those receiving care from non-primary care physicians, there was a slight increase in FOBT use between 2003 and $2005(P<.01)$. Those who did not have a usual place of health care had the lowest rates of testing: $21 \%$ had recent endoscopy in $2000,18 \%$ in 2003 , and $21 \%$ in $2005(P=.66)$; and the proportion of those unscreened increased during the study period $(P=.05)$.

Endoscopy use increased among enrollees in the 3 insurance groups during the 6 -year period, particularly among those with supplemental insurance (Figure 2). The trends in the pattern of screening among those on Medicare-only or Medicare-Medicaid were similar. Both had lower rates for recent endoscopy or FOBT and experienced no decline in FOBT use during the 6 -year period. Among those on supplemental insurance plans, rates of recent endoscopy increased along with decreasing FOBT use during the 6 -year period.
Among those who had delayed medical care, recent endoscopy rates increased from $31 \%$ in 2000 to $41 \%$ in 2005 , and FOBT use rates decreased from $14 \%$ to $10 \%$. Among those who had not delayed care, recent endoscopy rates increased from $38 \%$ in 2000 to $50 \%$ in 2005 , and FOBT use rates decreased from $15 \%$ to $10 \%$.

\section{Associations With Patterns of Screening}

Table 2 displays the unadjusted estimates of the associations between the selected health care access and utilization indicators and patterns of CRC screening for the 2000 and 2005 survey years. Those receiving care from non-primary care physicians were less likely to undergo recent endoscopy than those with a primary care physician. For both survey years, the largest difference for each CRC test was between those who did not have a usual place of health care and those who had received care from primary care physicians: the relative differences were larger in 2005 (unadjusted Wald $P$ values $=.03$ ). Those who delayed medical care because of cost were significantly less likely to undergo endoscopy or FOBT. 
Figure 2. Patterns of colorectal testing by type of insurance coverage among Medicare enrollees aged 65 to 80 years: MCBS 2000-2005.

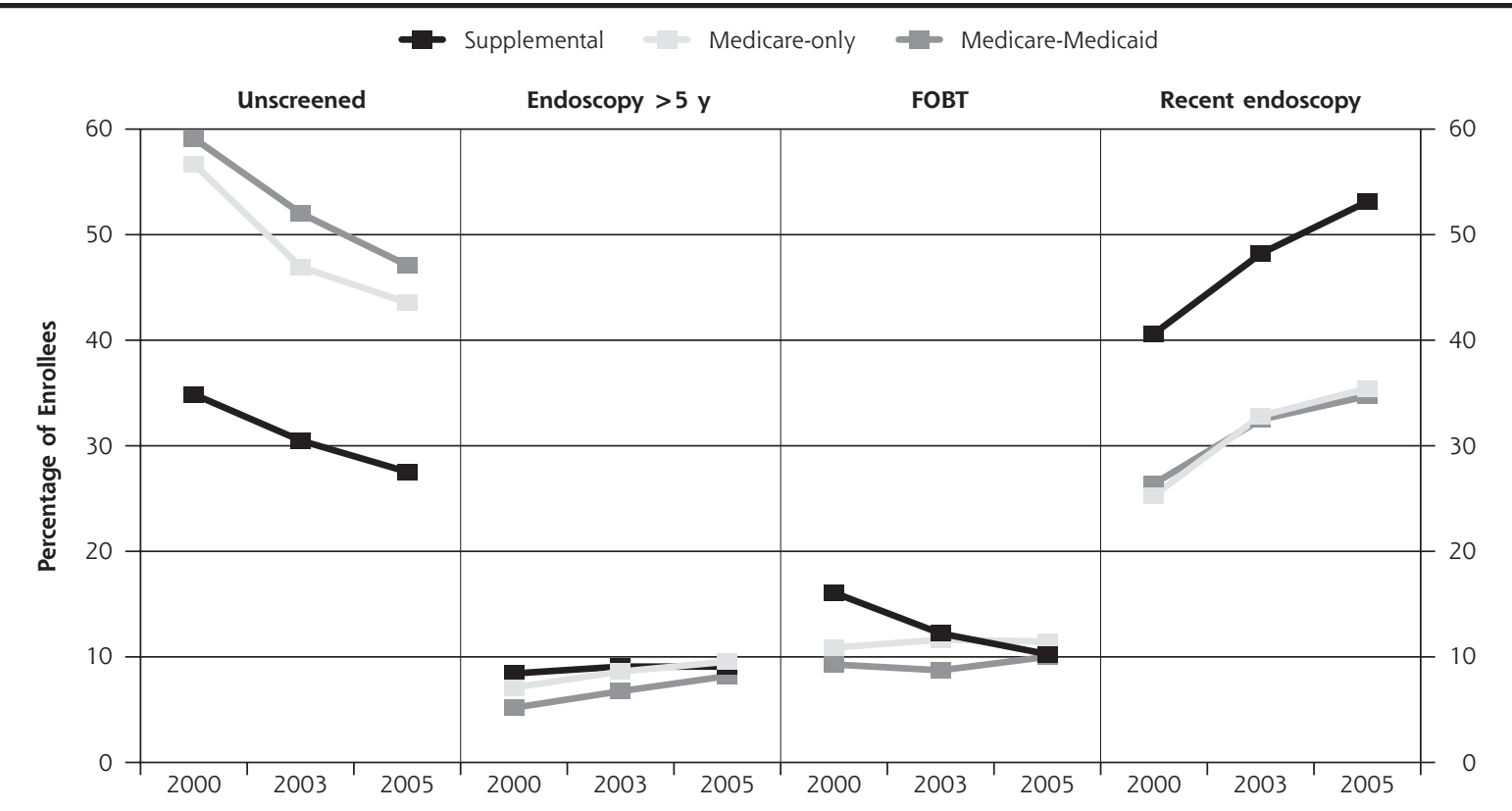

Endoscopy = sigmoidoscopy or colonoscopy; FOBT = home fecal occult blood test; $\mathrm{MCBS}=$ Medicare Current Beneficiary Survey; unscreened = enrollees who had never before been screened or only reported FOBT more than 2 years previously.

Note: The colorectal cancer testing categories are mutually exclusive.

Table 2. Unadjusted Associations of Access to Health Care With Patterns of Colorectal Cancer Testing Among Medicare Enrollees: MCBS 2000 and 2005

\begin{tabular}{|c|c|c|c|c|c|c|}
\hline \multirow[b]{3}{*}{ Study Parameters } & \multicolumn{6}{|c|}{$\begin{array}{l}\text { Unadjusted Odds Ratio }(95 \% \mathrm{Cl})^{\mathrm{a}} \\
\text { Study Year }\end{array}$} \\
\hline & \multicolumn{3}{|c|}{2000} & \multicolumn{3}{|c|}{2005} \\
\hline & $\begin{array}{c}\text { Endoscopy } \\
>5 \mathrm{y}\end{array}$ & FOBT & $\begin{array}{c}\text { Recent } \\
\text { Endoscopy }\end{array}$ & $\begin{array}{c}\text { Endoscopy } \\
>5 \mathrm{y}\end{array}$ & FOBT & $\begin{array}{c}\text { Recent } \\
\text { Endoscopy }\end{array}$ \\
\hline \multicolumn{7}{|l|}{ Usual place of health care } \\
\hline Primary care & Ref & Ref & Ref & Ref & Ref & Ref \\
\hline Non-primary care & $\begin{array}{c}1.08 \\
(0.81-1.45)\end{array}$ & $\begin{array}{c}0.91 \\
(0.75-1.09)\end{array}$ & $\begin{array}{c}0.83 \\
(0.72-0.96)\end{array}$ & $\begin{array}{c}0.88 \\
(0.69-1.14)\end{array}$ & $\begin{array}{c}1.12 \\
(0.86-1.46)\end{array}$ & $\begin{array}{c}0.83 \\
(0.68-1.02)\end{array}$ \\
\hline No usual place of care & $\begin{array}{c}0.95 \\
(0.69-1.30)\end{array}$ & $\begin{array}{c}0.25 \\
(0.18-0.36)\end{array}$ & $\begin{array}{c}0.31 \\
(0.24-0.41)\end{array}$ & $\begin{array}{c}0.37 \\
(0.25-0.56)\end{array}$ & $\begin{array}{c}0.16 \\
(0.10-0.26)\end{array}$ & $\begin{array}{c}0.18 \\
(0.14-0.24)\end{array}$ \\
\hline \multicolumn{7}{|l|}{ Insurance types } \\
\hline Medicare Part B only & $\begin{array}{c}0.52 \\
(0.35-0.76)\end{array}$ & $\begin{array}{c}0.42 \\
(0.31-0.57)\end{array}$ & $\begin{array}{c}0.38 \\
(0.31-0.48)\end{array}$ & $\begin{array}{c}0.66 \\
(0.51-0.86)\end{array}$ & $\begin{array}{c}0.71 \\
(0.54-0.92)\end{array}$ & $\begin{array}{c}0.42 \\
(0.35-0.51)\end{array}$ \\
\hline Medicare-Medicaid & $\begin{array}{c}0.36 \\
(0.26-0.51)\end{array}$ & $\begin{array}{c}0.34 \\
(0.27-0.43)\end{array}$ & $\begin{array}{c}0.38 \\
(0.32-0.46)\end{array}$ & $\begin{array}{c}0.53 \\
(0.41-0.68)\end{array}$ & $\begin{array}{c}0.57 \\
(0.42-0.77)\end{array}$ & $\begin{array}{c}0.38 \\
(0.31-0.46)\end{array}$ \\
\hline Supplemental Insurance & Ref & Ref & Ref & Ref & Ref & Ref \\
\hline Delayed medical care due to cost & $\begin{array}{c}0.92 \\
(0.63-1.34)\end{array}$ & $\begin{array}{c}0.74 \\
(0.56-0.98)\end{array}$ & $\begin{array}{c}0.67 \\
(0.53-0.84)\end{array}$ & $\begin{array}{c}1.03 \\
(0.74-1.43)\end{array}$ & $\begin{array}{c}0.75 \\
(0.52-1.06)\end{array}$ & $\begin{array}{c}0.68 \\
(0.55-0.84)\end{array}$ \\
\hline
\end{tabular}

In multivariable multinomial models, we examined the relationship between access to care and utilization indicators and CRC testing adjusted for age, race-ethnicity, sex, marital status, residence in metropolitan areas, educational achievement, income, self-reported health status, and history of cancer. We found significant interaction effects between insurance and educational attainment, particularly for recent colonoscopy use among less-educated Medicare-Medicaid enrollees. We also retained an interaction term for income and 


\begin{tabular}{|c|c|c|c|c|c|c|}
\hline \multirow[b]{3}{*}{ Study Parameters } & \multicolumn{6}{|c|}{$\begin{array}{l}\text { Adjusted Odds Ratio }(95 \% \mathrm{Cl})^{\text {a }} \\
\text { Study Year }\end{array}$} \\
\hline & \multicolumn{3}{|c|}{2000} & \multicolumn{3}{|c|}{2005} \\
\hline & $\begin{array}{l}\text { Endoscopy } \\
>5 \mathrm{y}\end{array}$ & FOBT & $\begin{array}{c}\text { Recent } \\
\text { Endoscopy }\end{array}$ & $\begin{array}{c}\text { Endoscopy } \\
>5 \mathrm{y}\end{array}$ & FOBT & $\begin{array}{c}\text { Recent } \\
\text { Endoscopy }\end{array}$ \\
\hline \multicolumn{7}{|l|}{ Usual place of health care } \\
\hline Primary care & Ref & Ref & Ref & Ref & Ref & Ref \\
\hline Non-primary care & $\begin{array}{c}1.23 \\
(0.92-1.65)\end{array}$ & $\begin{array}{c}0.99 \\
(0.80-1.22)\end{array}$ & $\begin{array}{c}0.92 \\
(0.79-1.08)\end{array}$ & $\begin{array}{c}0.96 \\
(0.74-1.23)\end{array}$ & $\begin{array}{c}1.21 \\
(0.92-1.60)\end{array}$ & $\begin{array}{c}0.94 \\
(0.76-1.16)\end{array}$ \\
\hline No usual source of care & $\begin{array}{c}1.05 \\
(0.76-1.45)\end{array}$ & $\begin{array}{c}0.27 \\
(0.19-0.39)\end{array}$ & $\begin{array}{c}0.35 \\
(0.27-0.46)\end{array}$ & $\begin{array}{c}0.39 \\
(0.26-0.59)\end{array}$ & $\begin{array}{c}0.18 \\
(0.11-0.30)\end{array}$ & $\begin{array}{c}0.22 \\
(0.17-0.30)\end{array}$ \\
\hline \multicolumn{7}{|l|}{ Insurance stratified by education } \\
\hline \multicolumn{7}{|l|}{ Less than high school } \\
\hline Medicare Part B only & $\begin{array}{c}0.39 \\
(0.25-0.62)\end{array}$ & $\begin{array}{c}0.60 \\
(0.36-0.98)\end{array}$ & $\begin{array}{c}0.52 \\
(0.39-0.70)\end{array}$ & $\begin{array}{c}1.00 \\
(0.63-1.59)\end{array}$ & $\begin{array}{c}0.84 \\
(0.49-1.43)\end{array}$ & $\begin{array}{c}0.70 \\
(0.48-1.01)\end{array}$ \\
\hline Medicare-Medicaid & $\begin{array}{c}0.37 \\
(0.21-0.64)\end{array}$ & $\begin{array}{c}0.43 \\
(0.29-0.64)\end{array}$ & $\begin{array}{c}0.80 \\
(0.63-1.02)^{b}\end{array}$ & $\begin{array}{c}0.72 \\
(0.50-1.05)\end{array}$ & $\begin{array}{c}0.91 \\
(0.61-1.35)\end{array}$ & $\begin{array}{c}0.81 \\
(0.60-1.09)\end{array}$ \\
\hline Supplemental insurance & Ref & Ref & Ref & Ref & Ref & Ref \\
\hline \multicolumn{7}{|l|}{ High school diploma or higher } \\
\hline Medicare Part B only & $\begin{array}{c}0.84 \\
(0.48-1.46)\end{array}$ & $\begin{array}{c}0.62 \\
(0.44-0.89)\end{array}$ & $\begin{array}{c}0.61 \\
(0.46-0.80)\end{array}$ & $\begin{array}{c}0.80 \\
(0.56-1.16)\end{array}$ & $\begin{array}{c}1.05 \\
(0.78-1.41)\end{array}$ & $\begin{array}{c}0.57 \\
(0.44-0.73)\end{array}$ \\
\hline Medicare-Medicaid & $\begin{array}{c}0.65 \\
(0.38-1.11)\end{array}$ & $\begin{array}{c}0.55 \\
(0.38-0.81)\end{array}$ & $\begin{array}{c}0.41 \\
(0.29-0.58)^{b}\end{array}$ & $\begin{array}{c}0.70 \\
(0.46-1.08)\end{array}$ & $\begin{array}{c}0.86 \\
(0.52-1.44)\end{array}$ & $\begin{array}{c}0.53 \\
(0.39-0.71)\end{array}$ \\
\hline Supplemental insurance & Ref & Ref & Ref & Ref & Ref & Ref \\
\hline Delayed medical care due to cost & $\begin{array}{c}1.14 \\
(0.78-1.67)\end{array}$ & $\begin{array}{c}1.10 \\
(0.81-1.49)\end{array}$ & $\begin{array}{c}1.00 \\
(0.79-1.27)\end{array}$ & $\begin{array}{c}1.35 \\
(0.95-1.92)\end{array}$ & $\begin{array}{c}1.04 \\
(0.71-1.52)\end{array}$ & $\begin{array}{c}1.06 \\
(0.85-1.33)\end{array}$ \\
\hline
\end{tabular}

residence in metropolitan areas in the multivariable models, based on previous analyses. ${ }^{23}$

In 2000, the difference in use of recent endoscopy between those receiving care from primary care physicians and non-primary care physicians was statistically significant even after controlling for age, sex, and marital status in the model $(\mathrm{OR}=0.84 ; 95 \%$ CI, 0.72-0.97), but the differences were not significant after adjustment for race-ethnicity alone in the model $(\mathrm{OR}=0.88 ; 95 \% \mathrm{CI}, 0.76-1.02)$. In each survey year, compared with those receiving care from primary care physicians, enrollees with no usual place of health care had significantly lower rates of recent endoscopy or FOBT use (Table 3). These differences were larger in 2005 than 2000, corroborating the wider gap between those with and without a usual place of care in the most recent study year as shown in Figure 1.

Multivariable analyses of the association with type of insurance coverage were stratified by level of education using the insurance-education interaction term (Table 3). Among beneficiaries with less than a high school diploma, those on Medicare-only or MedicareMedicaid were less likely to undergo endoscopy or
FOBT in 2000, but the differences were attenuated in 2005. Among more educated enrollees, there were significant differences in rates of recent endoscopy and FOBT by type of insurance coverage in 2000, and a statistically significant difference in FOBT use remained in 2005. In 2000, the relative difference in recent endoscopy for Medicare-Medicaid enrollees with a high school diploma or higher was significantly larger than the estimate for those less educated (Bonferonni adjusted $P$ value $=.01$ ).

In 2000, the association between delaying medical care because of cost and use of recent endoscopy was stable to adjustment in the base model (excluding place of residence) $(\mathrm{OR}=0.71 ; 95 \% \mathrm{CI}, 0.56-0.89)$ and to further adjustment for usual place of health care $(\mathrm{OR}=0.77 ; 95 \% \mathrm{CI}, 0.61-0.98)$. With further addition of health insurance in the model, the association was no longer statistically significant $(\mathrm{OR}=0.90 ; 95 \%$ CI, 0.72-1.13). The findings were similar in 2005; the association was stable to adjustment in the base model $(\mathrm{OR}=0.78 ; 95 \% \mathrm{CI}, 0.62-0.96)$, but not to further adjustment for usual place of care $(\mathrm{OR}=0.89 ; 95 \% \mathrm{CI}$, $0.71-1.11)$ and health insurance $(\mathrm{OR}=0.97 ; 95 \% \mathrm{CI}$, 0.77-1.22). 


\section{DISCUSSION}

Despite expanding coverage for CRC screening, which primarily benefited those without supplemental insurance, Medicare enrollees who did not have supplemental insurance or a usual place of health care had disproportionally lower rates of CRC testing. This finding suggests that expanding health insurance benefits without additional targeted efforts to improve utilization of appropriate health care services will not eliminate disparities. During the 6-year study period, the proportion that remained unscreened increased among enrollees without a usual source of health care, resulting in a widening gap in use of CRC testing compared with those receiving their usual care from primary care physicians. In addition, the disparity in use of lower endoscopy persisted for Medicare-only or MedicareMedicaid insured enrollees.

Previous studies found that lack of adequate health insurance or a usual place of health care was associated with lower screening rates. ${ }^{6,11-13}$ This study found that disparities for those without a place of health care widened over the 6 -year period. We found similar unadjusted differences in use of recent endoscopy by specialty of the usual physician during the study period. Our study also found that disparities persisted in 2005 for those who may not be able to afford the costs of health care, but the disparities were not significant after adjustment for health insurance and usual place of care. There also remained persistent disparities in use of endoscopy for more-educated Medicare enrollees who did not have supplemental insurance.

These findings reinforce the important role of primary care ${ }^{8-11,32}$ and the potential role of a patient-centered medical home ${ }^{33}$ in the delivery of CRC screening services. A physician recommendation is one of the strongest predictors of screening. ${ }^{32,34,35}$ Those without a usual source of care may not have an opportunity to receive such recommendations. ${ }^{36}$ Interestingly, enrollees who received their usual care in non-primary care settings had lower rates of recent endoscopy than those who received care in primary care settings, but differences were not significant after adjustment for race-ethnicity. Fragmentation of health care delivery may negatively affect the delivery of CRC screening services. Accordingly, better coordination of the care provided by primary care and subspecialty physicians, targeted outreach programs, in-office or mailed reminder systems, ${ }^{37}$ and offering appropriate screening services at each medical encounter may increase use of screening among patients, ${ }^{36}$ particularly for those who do not receive regular care in primary care settings.

Factors that limit access to health care are major barriers to cancer screening. ${ }^{32}$ We found that those who delayed medical care because of cost were less likely to undergo CRC testing than those who did not delay care, but the differences were attenuated after controlling for the type of health insurance coverage. This finding reinforces the interrelatedness of factors related to health care access, including low income or education and lack of adequate health insurance; they tend to occur together and cumulate in the same persons. ${ }^{38,39}$ In this study, the recent endoscopy rate in 2000 among those on supplemental health insurance plans was higher than the rate in 2005 among enrollees without supplemental insurance; the gap narrowed in 2005. Benefits for CRC screening vary among health insurance plans. ${ }^{40}$ Cost-sharing schemes decrease colonoscopy use ${ }^{41,42}$ and may disproportionally affect those without supplemental insurance. Medicare pays up to $80 \%$ of allowed cost of screening colonoscopy, about $\$ 622$ to $\$ 811$ in 2007 dollars depending on the complexity of the procedure. ${ }^{16,43}$

Although the persistent gap with respect to endoscopy testing by insurance was notable, it was striking that disparities were greater for more educated enrollees on Medicaid-Medicare compared with those less educated. Medicaid eligibility is based on poverty; underlying reasons for Medicaid eligibility for more educated enrollees may further impede their ability to undergo CRC screening.

Surprisingly, we found persistent disparities in FOBT testing in 2000 by insurance coverage. The differences in FOBT use, however, were attenuated in the most recent study year because more enrollees with supplemental insurance switched to endoscopy, resulting in a sharp decline in FOBT testing in this group compared with those without supplemental insurance.

There are some limitations of this study. We did not have data to track the full health care utilization history of study patients to determine whether the reported place of usual care correlated with the specialty of the physician or actual health care visits. Because MCBS did not distinguish between sigmoidoscopy and colonoscopy, we used a 5 -year cutoff to define endoscopy use and provided findings about endoscopies done more than 5 years previously. Further, enrollees may not have accurately recalled the use of, type of, or the indication for CRC testing. Consequently, the decline in FOBT use and increase in endoscopy may result from improved follow-up of abnormal FOBT results. Even so, we found no change in the proportion of enrollees reporting both recent endoscopy and FOBT during the study period.

In summary, despite expanding coverage for screening, there remained complex disparities in CRC testing among Medicare beneficiaries as a result of differences in the setting and cost of health care, type of health insurance coverage, and level of education. Outreach 
programs that include efforts to encourage enrollees to have regular visits with a primary care physician and to undergo an annual preventive health examination, ${ }^{36,44}$ as well as reminder systems for patients and primary care physicians to consider all screening options carefully, including FOBT, may further increase CRC screening rates and mitigate disparities for vulnerable populations. ${ }^{45}$ As recommended for improving the care of cancer survivors, ${ }^{46}$ it may be possible to increase screening rates through better coordination of preventative care between specialists and primary care physicians, but this possibility needs further study.

To read or post commentaries in response to this article, see it online at http://www.annfammed.org/cgi/content/full/8/4/299.

Key words: Colorectal cancer; cancer screening tests; health care disparities; cost of health care; insurance; health; physician's practice patterns

Submitted March 2, 2009; submitted, revised, November 3, 2009; accepted November 30, 2009.

Funding support: Dr Doubeni is supported by a National Cancer Institute career development award (5K01CA127118-03).

\section{References}

1. Mandel JS, Bond JH, Church TR, et al. Reducing mortality from colorectal cancer by screening for fecal occult blood. Minnesota Colon Cancer Control Study. N Engl J Med. 1993;328(19):1365-1371.

2. Selby JV, Friedman GD, Quesenberry CP Jr, Weiss NS. A case-control study of screening sigmoidoscopy and mortality from colorectal cancer. N Engl J Med. 1992;326(10):653-657.

3. Winawer SJ, Zauber AG, Ho MN, et al; The National Polyp Study Workgroup. Prevention of colorectal cancer by colonoscopic polypectomy. N Engl J Med. 1993;329(27):1977-1981.

4. Centers for Disease Control and Prevention (CDC). Use of colorectal cancer tests-United States, 2002, 2004, and 2006. MMWR Morb Mortal Wkly Rep. 2008;57(10):253-258.

5. Shapiro JA, Seeff LC, Thompson TD, Nadel MR, Klabunde CN, Vernon SW. Colorectal cancer test use from the 2005 National Health Interview Survey. Cancer Epidemiol Biomarkers Prev. 2008;17(7): 1623-1630.

6. Seeff LC, Nadel MR, Klabunde CN, et al. Patterns and predictors of colorectal cancer test use in the adult U.S. population. Cancer. 2004;100(10):2093-2103.

7. Chen X, White MC, Peipins LA, Seeff LC. Increase in screening for colorectal cancer in older Americans: results from a national survey. J Am Geriatr Soc. 2008;56(8):1511-1516.

8. Bindman AB, Grumbach K, Osmond D, Vranizan K, Stewart AL. Primary care and receipt of preventive services. J Gen Intern Med. 1996;11(5):269-276.

9. Meissner HI, Breen N, Klabunde CN, Vernon SW. Patterns of colorectal cancer screening uptake among men and women in the United States. Cancer Epidemiol Biomarkers Prev. 2006;15(2):389-394.

10. Etzioni DA, Yano EM, Rubenstein LV, et al. Measuring the quality of colorectal cancer screening: the importance of follow-up. Dis Colon Rectum. 2006;49(7):1002-1010.

11. DeVoe JE, Fryer GE, Phillips R, Green L. Receipt of preventive care among adults: insurance status and usual source of care. Am J Public Health. 2003;93(5):786-791.
12. Robinson JM, Shavers $\mathrm{V}$. The role of health insurance coverage in cancer screening utilization. J Health Care Poor Underserved. 2008;19(3):842-856.

13. Schneider EC, Rosenthal M, Gatsonis CG, Zheng J, Epstein AM. Is the type of Medicare insurance associated with colorectal cancer screening prevalence and selection of screening strategy? Med Care 2008;46(9)(Suppl 1):S84-S90

14. Ioannou GN, Chapko MK, Dominitz JA. Predictors of colorectal cancer screening participation in the United States. Am J Gastroenterol. 2003;98(9):2082-2091.

15. Koroukian SM, Xu F, Dor A, Cooper GS. Colorectal cancer screening in the elderly population: disparities by dual Medicare-Medicaid enrollment status. Health Serv Res. 2006;41(6):2136-2154.

16. Centers for Medicare and Medicaid Services. National Medicare Handbook. Medicare and You, 2009. CMS Publication No. 10050. 2008. http://www.medicare.gov/publications/pubs/pdf/10050.pdf.

17. Jonas DE, Russell LB, Sandler RS, Chou J, Pignone M. Value of patient time invested in the colonoscopy screening process: time requirements for colonoscopy study. Med Decis Making. 2008; 28(1):56-65.

18. Fenton JJ, Cai Y, Green P, Beckett LA, Franks P, Baldwin LM. Trends in colorectal cancer testing among Medicare subpopulations. Am J Prev Med. 2008;35(3):194-202.

19. Marbet UA, Bauerfeind P, Brunner J, Dorta G, Valloton JJ, Delcò F. Colonoscopy is the preferred colorectal cancer screening method in a population-based program. Endoscopy. 2008;40(8):650-655.

20. Schenck AP, Peacock SC, Klabunde CN, Lapin P, Coan JF, Brown $\mathrm{ML}$. Trends in colorectal cancer test use in the medicare population, 1998-2005. Am J Prev Med. 2009;37(1):1-7.

21. Atherly A. Supplemental insurance: Medicare's accidental stepchild. Med Care Res Rev. 2001;58(2):131-161.

22. Adler GS. A profile of the Medicare Current Beneficiary Survey. Health Care Financ Rev. 1994;15(4):153-163.

23. Doubeni CA, Laiyemo AO, Reed G, Field TS, Fletcher RH. Socioeconomic and racial patterns of colorectal cancer screening among Medicare enrollees in 2000 to 2005. Cancer Epidemiol Biomarkers Prev. 2009;18(8):2170-2175.

24. U.S. Preventive Services Task Force. Screening for colorectal cancer: U.S. Preventive Services Task Force recommendation statement. Ann Intern Med. 2008;149(9):627-637.

25. National Committee for Quality Assurance (NCQA). Colorectal cancer screening: percentage of adults 50 to 80 years of age who had appropriate screening for colorectal cancer. In: HEDIS 2008: Healthcare Effectiveness Data \& Information Set. Vol. 2, Technical Specifications. http://www.qualitymeasures.ahrq.gov/summary/summary. aspx?doc_id=13036.

26. Doubeni CA, Laiyemo AO, Klabunde C, Young AC, Field TS, Fletcher RH. Racial and ethnic trends of colorectal cancer screening among Medicare enrollees. Am J Prev Med. 2010;38(2):184-191.

27. Levin B, Lieberman DA, McFarland B, et al.; American Cancer Society Colorectal Cancer Advisory Group; US Multi-Society Task Force; American College of Radiology Colon Cancer Committee. Screening and surveillance for the early detection of colorectal cancer and adenomatous polyps, 2008: a joint guideline from the American Cancer Society, the US Multi-Society Task Force on Colorectal Cancer, and the American College of Radiology. Gastroenterology. 2008;134(5):1570-1595.

28. Centers for Medicare and Medicaid Services. Appendix A: technical documentation for the Medicare Current Benefificiary Survey. Health \& Health Care of the Medicare Population: 2002. 2002. http:// www.cms.hhs.gov/mcbs/downloads/HHC2002appendixA.pdf.

29. Archer KJ, Lemeshow S. Goodness-of-fit test for a logistic regression model fitted using survey sample data. The Stata Journal. 2006;6(1):97-105. 
30. Begg CB, Gray R. Calculation of polychotomous logistic regression parameters using individualized regressions. Biometrika. 1984;71(1):11-18

31. Korn EL, Graubard BI. Simultaneous testing of regression coefficients with complex survey data: use of Bonferroni $t$ statistics. Am Stat. 1990;44(4):270-276

32. Klabunde CN, Schenck AP, Davis WW. Barriers to colorectal cancer screening among Medicare consumers. Am J Prev Med. 2006;30(4):313-319.

33. Rittenhouse DR, Shortell SM. The patient-centered medical home: will it stand the test of health reform? JAMA. 2009;301(19): 2038-2040.

34. Levy BT, Joshi M, Xu Y, Daly J, James PA. Perceptions of lowa family physicians regarding colorectal cancer screening. Med Care. 2008;46(9)(Suppl 1):S103-S108.

35. Wee CC, McCarthy EP, Phillips RS. Factors associated with colon cancer screening: the role of patient factors and physician counseling. Prev Med. 2005;41(1):23-29.

36. Klabunde CN, Vernon SW, Nadel MR, Breen N, Seeff LC, Brown $\mathrm{ML}$. Barriers to colorectal cancer screening: a comparison of reports from primary care physicians and average-risk adults. Med Care 2005;43(9):939-944.

37. Sequist TD, Zaslavsky AM, Marshall R, Fletcher RH, Ayanian JZ. Patient and physician reminders to promote colorectal cancer screening: a randomized controlled trial. Arch Intern Med. 2009;169(4):364-371.

38. Fiscella K, Williams DR. Health disparities based on socioeconomic inequities: implications for urban health care. Acad Med. 2004;79(12):1139-1147.
39. Ayanian JZ, Weissman JS, Schneider EC, Ginsburg JA, Zaslavsky AM. Unmet health needs of uninsured adults in the United States. JAMA. 2000;284(16):2061-2069.

40. Klabunde CN, Riley GF, Mandelson MT, Frame PS, Brown ML. Health plan policies and programs for colorectal cancer screening: a national profile. Am J Manag Care. 2004;10(4):273-279.

41. Adams EK, Thorpe KE, Becker ER, Joski PJ, Flome J. Colorectal cancer screening, 1997-1999: role of income, insurance and policy. Prev Med. 2004;38(5):551-557.

42. Wharam JF, Galbraith AA, Kleinman KP, Soumerai SB, Ross-Degnan $D$, Landon BE. Cancer screening before and after switching to a high-deductible health plan. Ann Intern Med. 2008;148(9):647-655.

43. Zauber AG, Knudsen AB, Rutter CM, et al. Cost-effectiveness of CT colonography to screen for colonorectal cancer. CMS Technology Assessment Report. 2009. http://www1.cms.hhs.gov/determinationprocess/downloads/id58TA.pdf.

44. Fenton JJ, Cai Y, Weiss NS, et al. Delivery of cancer screening: how important is the preventive health examination? Arch Intern Med. 2007;167(6):580-585.

45. Vernon SW. Participation in colorectal cancer screening: a review. J Natl Cancer Inst. 1997;89(19):1406-1422.

46. Committee on Cancer Survivorship. Improving Care and Quality of Life National Policy Board. Delivering cancer survivorship care. In: Hewitt M, Greenfield S, Stovall E, eds. From Cancer Patient to Cancer Survivor: Lost in Transition. Washington, DC: Institute of Medicine; 2005:187-321. 